\title{
Multi-Ensayos
}

Vol. 4, $\mathrm{N}^{\circ} 7$

ISSN: 2412-3285

https://multiensayos.unan.edu.ni

DOI: https://doi.org/10.5377/multiensayos.v4i7.9487

\section{La ética profesional en el desempeño del contador público egresado de la UNAN Managua-FAREM Estelí}

\section{Importance of Professional Ethics in the Performance Public Accountant Students of UNAN Managua-FAREM Estelí}

\author{
Karla Nolaska Peña Navarrete ${ }^{1}$
}

Recibido: 05 de marzo de 2018, Aceptado: 27 de septiembre de 2018

\section{RESUMEN}

La carrera de Contaduría Pública ofertada por la Universidad Nacional Autónoma de Nicaragua, Managua, desde la Facultad Regional Multidisciplinaria de Estelí, es una de las más demandadas por instituciones públicas y privadas de la región norte del país. Por lo tanto, es determinante que los estudiantes en su formación, incorporen y apliquen los conocimientos sobre el papel de la ética profesional en su desempeño personal y profesional. Un profesional egresado de esta carrera, tiene el reto de convertirse en una persona influyente en las áreas de contabilidad, finanzas, costos y auditoría. Todo ello implica la responsabilidad intrínseca de aprender y luchar por enlazar los conocimientos técnicos con los principios éticos, en actitud crítica, objetiva, proactiva y de compromiso en el ejercicio de su profesión, siendo la piedra angular sobre la cual debe sostenerse ese esfuerzo.

Palabras claves: ética profesional; principios éticos; contador público; desempeño profesional.

\section{ABSTRACT}

The Public Accounting major, offered by the National Autonomous University of Nicaragua through the Regional Multidisciplinary Faculty of Estelí, is one of the most demanded by public and private institutions in the northern region of the country. So, it is crucial to incorporate elements in students' training to make them aware of the role of professional ethics in their personal and professional performance. As graduated professional they will be challenged to become an influential person in the areas of accounting, finance, costs and auditing. The inclusion of these elements imply the intrinsic responsibility to learn and continuously relate the technical knowledge with ethical principles. It also means they will have to commit themselves to the ethical practice of their profession as it is the cornerstone on which they must sustain their efforts.

Keywords: professional ethics; ethical principles; public accountant; professional performance.

1 Docente del Departamento de Ciencias Económicas y Administrativas, UNAN-Managua/FAREM-Estelí. Correo electrónico: karlap_25@ yahoo.es

Copyright (c) 2018 Revista Multi-Ensayos. 


\section{INTRODUCCIÓN}

El presente escrito aborda la importancia de la ética profesional en el desempeño de un contador público egresado de la Universidad Nacional Autónoma de Nicaragua, Managua, particularmente de la Facultad Regional Multidisciplinaria Estelí.

Todo contador público, tienen el reto de convertirse en un profesional destacado en las áreas de su formación como es la contabilidad, finanzas, costos y auditoría. Sin embargo, más que la preparación técnica, implica la gran responsabilidad de enlazar y poner en práctica esos conocimientos con los principios éticos y morales, en una actitud crítica, objetiva, con una conducta proactiva y de compromiso en el ejercicio de su profesión. De igual manera, como depositario de la confianza pública, "da fe" cuando suscribe un documento que expresa su opinión sobre determinados hechos económicos pasados, presentes o futuros.

El objetivo del presente ensayo, es reflexionar acerca de la importancia que tiene la puesta en práctica de los valores éticos en el desempeño profesional del contador público egresado de la FAREM Estelí, como finalidad del bien común y del público en general, en una dimensión social y de servicio a la comunidad. De manera particular, se abordan temas fundamentales tales como: el objetivo de la ética en la profesión del contador público, la importancia de la aplicación del código de ética profesional la cual es de vital importancia en el ejercicio de su profesión y por último las normas generales y principios básicos aplicables a la profesión del contador público.

\section{DESARROLLO}

La palabra ética proviene del griego "ethos" que quiere decir hábito o costumbre. A partir de éste término, se usó ésta expresión que significa modo de ser o carácter. Muchas veces se confunde la ética y la moral. Pero, es necesario recordar que moral es el conjunto de reglas, valores, y prohibiciones procedentes de factores externos, es decir, que al hombre le son inculcados o impuestos por la política, las costumbres sociales, la religión o las ideologías. En cambio la ética siempre implica una reflexión teórica sobre cualquier moral, una revisión racional y crítica sobre la validez de la conducta humana.

La ética es una ciencia práctica y normativa que estudia racionalmente el comportamiento de los humanos en sus actos diarios. Además, es el juicio del actuar que tenemos todos los seres humanos frente a nuestros semejantes y la forma en la que nos desenvolvemos en nuestras actividades diarias. En decir, la ética es la ciencia de la conducta humana.

Desde el punto de vista conceptual, la ética es una ciencia, porque es una disciplina racional ya que parte de los actos humanos y los transporta hasta llegar a sus principios. Es un conjunto de conocimientos sistemáticos, metódicos y racionales basados en la experiencia y fundados en principios. (Torres Hernández, 2014)

La Ética Profesional en conclusión, puede definirse como el conjunto de normas y principios asumidos voluntariamente por quienes ejercen una determinada profesión, por razones de integridad, de profesionalismo, de responsabilidad social. 
La sociedad en general y las empresas en particular, son unidades económicas sometidas a variadas influencias externas. El contador público en el desarrollo de su actividad profesional deberá utilizar en cada caso los métodos de análisis y evaluación más apropiados para la situación que se presenta, dentro de los lineamientos dados por la profesión y podrá además, recurrir a especialistas de disciplinas diferentes a la contaduría pública y a la utilización de todos los elementos que la ciencia y la técnica ponen a su disposición.

En la formación profesional, se enfatiza que un contador público, deberá de analizar al usuario de sus servicios como ente económico independiente, observando en todos los casos los principios y el conocimiento y aplicación de lo normado en el código de ética profesional, el cual es de vital importancia en su desempeño profesional.

Los colegios profesionales, tienen entre sus funciones la emisión y vigilancia de normas que rijan a los profesionales en el ejercicio de su actividad, y tienen la potestad de fijar normas deontológicas que adaptadas a las realidades de cada profesión, ayuden por un lado a definir con claridad la conducta ética deseable de sus profesionales y por otro lado, eviten comportamientos no deseados que redunden en un desmérito de la profesión en general que desprestigie al colectivo de profesionales que la ejerce, la defensa de los destinatarios de los servicios de nuestros profesionales y la función social que cumplen los colegios profesionales así lo demanda. (Munch, 2015, pág. 53)

Los códigos de ética son las normas en que se expresan las ideas centrales de la conducta corporativa, de este modo los códigos ejercen una función regulativa y directiva al indicar los valores colectivos, los gestos diferenciadores, los compromisos colectivamente contraídos, los códigos desempeñan una función identificadora de la profesión ante la profesión misma. (Alatrista Gironzini, 2015). Por tanto, en la formación de nuestros profesionales, se enfatiza en estas competencias que tendrán que desarrollar nuestros egresados.

El Colegio de Contadores Públicos de Nicaragua (CCPN), organismo rector de la profesión contable en Nicaragua y miembro de la Federación Internacional de Contadores (IFAC), con el propósito de normar la actuación en el ejercicio de la profesión de los Contadores Públicos Autorizados (CPA) y Contadores Públicos (CP); y proyectar la profesión a mayores niveles de credibilidad y autoridad ante los usuarios de sus servicios y público en general, ha elaborado un código de ética que rige a todos los contadores públicos afiliados al mismo. El término profesional de la contabilidad comprende ambas categorías del profesional de la contaduría pública en el territorio nicaragüense. (Colegio de Contadores Públicos de Nicaragua, 2009)

El manejo de esta información existente en el código de ética, es de gran importancia, dado que sirve de guía y referencia en la actuación profesional, especialmente en el ejercicio de su profesión al mantener su independencia de acción, para no subordinar su criterio ni lesionar su imparcialidad al examinar los estados financieros de una empresa a la que preste sus servicios.

Es importante mencionar, que en nuestra Facultad, en relación a la formación profesional de los Contadores Públicos, se enfatiza en la importancia de que en el ejercicio de la profesión ni aún en su vida privada, 
debe cometer ningún acto que desacredite la profesión. Por tanto y en consecuencia, deberá cimentar su reputación en la honradez, laboriosidad, buenas costumbres y capacidad profesional, observando las normas de ética profesional más elevadas en todos sus actos, así como el debido decoro en su vida privada. Toda asociación o vinculación del nombre del Contador en relación a responsabilidades que ha tenido de su cargo deberá basarse en lo dispuesto por las normas de auditoría generalmente aceptadas. (Colegio de Contadores Públicos de Nicaragua, 2009)

De acuerdo con este colegio, se deben de tomar en cuenta un conjunto de normas y principios, que tengan por objetivo, orientar la actuación profesional, dentro de los marcos del honor, dignidad y capacidad profesional, actuando con probidad y buena fe, en todos sus actos, los cuales se describen a continuación:

a. Integridad: ser franco y honesto en todas las relaciones profesionales y empresariales.

b. Objetividad: hacer prevalecer los juicios profesionales o empresariales sobre prejuicios, conflicto de interés o influencia de terceros.

c. Competencia y diligencia profesional: mantener el conocimiento y la aptitud profesional y actuar diligentemente para asegurarle al cliente o la entidad para quien trabaje los servicios profesionales competentes, basados en los últimos avances de la práctica, legislación y las técnicas profesionales aplicables.

d. Confidencialidad: respetar la confidencialidad de la información, obtenida como resultado de relaciones profesionales y empresariales; y guardar el sigilo de la misma de terceros sin autorización adecuada y especifica de conocerla, salvo que exista un derecho o deber legal o profesional de revelarla; no hacer uso de la información en provecho propio o de terceros.

e. Comportamiento profesional: cumplir las disposiciones legales y reglamentarias aplicables y evitar cualquier actuación que pueda desacreditar a la profesión.

f. Conciencia moral: al desarrollarse la actividad del profesional de la contabilidad en un medio social, debe cumplir estrictamente normas y preceptos que regulan su conducta. La parte de su espíritu que siempre le dirá si cumple o deja de cumplir sus deberes es la "Conciencia Moral".

g. Equidad y justicia: así como la equidad y la justicia son los postulados básicos de las normas o principios de contabilidad, estos lo son también de la ética profesional del contador público.

h. Independencia: El profesional de la contabilidad no puede aceptar ninguna situación, hecho o circunstancia, que le impongan condiciones en la libre adopción de sus decisiones y el libre ejercicio de su práctica profesional.

i. Responsabilidad: la responsabilidad moral garantiza el cumplimiento cabal, justo y oportuno de los compromisos, deberes y obligaciones.

j. Veracidad y lealtad: la veracidad es reflejo de la realidad. Por ello, el profesional de la contabilidad, actuando de manera independiente, hace constar todos los datos importantes de que tenga conocimiento en relación con la situación financiera o con los resultados de operaciones de sus clientes.

En la ética profesional de los contadores públicos existen normas de conductas generales las cuales son de ineludible cumplimiento que sirven de guía en la aplicación de los principios independiente al medio social en que se desenvuelve, contribuyendo de esta forma en las relaciones que mantiene con el público en general con sus colegas profesionales, con la clientela a la cual prestan sus servicios ya sea que actúen individualmente o como integrantes de una firma de contadores públicos autorizados. Una de las normas 
que establece el (Colegio de Contadores Públicos de Nicaragua, 2009), es “El Contador Público deberá cimentar su reputación en la honradez, laboriosidad y capacidad profesional, observando los principios y normas de ética profesional más elevadas en todos sus actos, así corno el debido decoro en su vida privada".

La FAREM Estelí se ha caracterizado en tener una planta docente con altos valores y principios éticos y morales, actuando con actitud crítica y objetiva y enfatizándose en el desarrollo de competencias en la formación de valores del estudiantado, al insertar en cada asignatura desde su ámbito y naturaleza la ética profesional que debe reflejar cada egresado en el campo laboral, como lo es la responsabilidad, actitud profesional, objetividad, entre otros.

\section{CONCLUSIONES}

El profesional contable egresado de UNAN-Managua- FAREM- Estelí no solo debe adquirir conocimientos contables, sino también poner en práctica los conocimientos éticos y de valores aprendidos, como instrumentos básicos que refuerzan la construcción de un profesional integral.

Es de suma importancia conocer que existe un código de ética del contador público publicado y avalado por el Colegio de Contadores Públicos de Nicaragua el cual sirve de guía y referencia en la actuación profesional especialmente en el ejercicio de su profesión al mantener su independencia de acción.

La identificación de principios y normas sirven de guía en la actuación profesional del contador público, dentro del marco del honor, dignidad y capacidad profesional, contribuyendo en la actuación con probidad y buena fe, en todos sus actos.

El egresado de Contaduría Pública está en la obligación tanto social como profesional, de ser un abanderado de la verdad, promulgar siempre la ética y el respeto, la transparencia y la honestidad en el ejercicio de su profesión, siendo ejemplo claro para los futuros profesionales contables, lo cual sirve de reto para los docentes al desarrollar competencias en la formación de valores en el estudiantado.

\section{BIBLIOGRAFÍA}

Alatrista Gironzini, M. A. (2015). Ética del Contador Público. Revista de Contabilidad y Dirección, 119130.

Colegio de Contadores Públicos de Nicaragua. (2009). Código de Ética. Managua, Nicaragua: IFAC AIC. Herrera Pérez, D. J. (1959). El contador público y la ética.

Munch, L. (2015). Ética y valores. Editorial Trillas. México, D.F.

Torres Hernández, Z. (2014). Introducción a la Ética. México: Grupo editorial Patria. 